\title{
Advanced Test Reactor National Scientific User Facility (ATR NSUF)
}

\author{
Renae Soelberg
}

November 2014

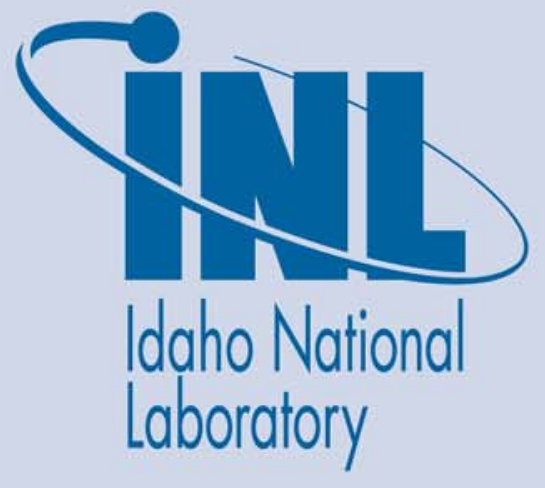

The INL is a U.S. Department of Energy National Laboratory operated by Battelle Energy Alliance 
INL/EXT-15-33994

\title{
Advanced Test Reactor National Scientific User Facility (ATR NSUF) Monthly Report
}

\author{
Renae Soelberg
}

November 2015

\author{
Idaho National Laboratory \\ Idaho Falls, Idaho 83415
}

http://www.inl.gov

Prepared for the

U.S. Department of Energy

Office of Nuclear Energy

Under DOE Idaho Operations Office

Contract DE-AC07-05ID14517 


\title{
Advanced Test Reactor National Scientific User Facility (ATR NSUF) Monthly Report
}

\author{
November 2014
}

\section{Highlights}

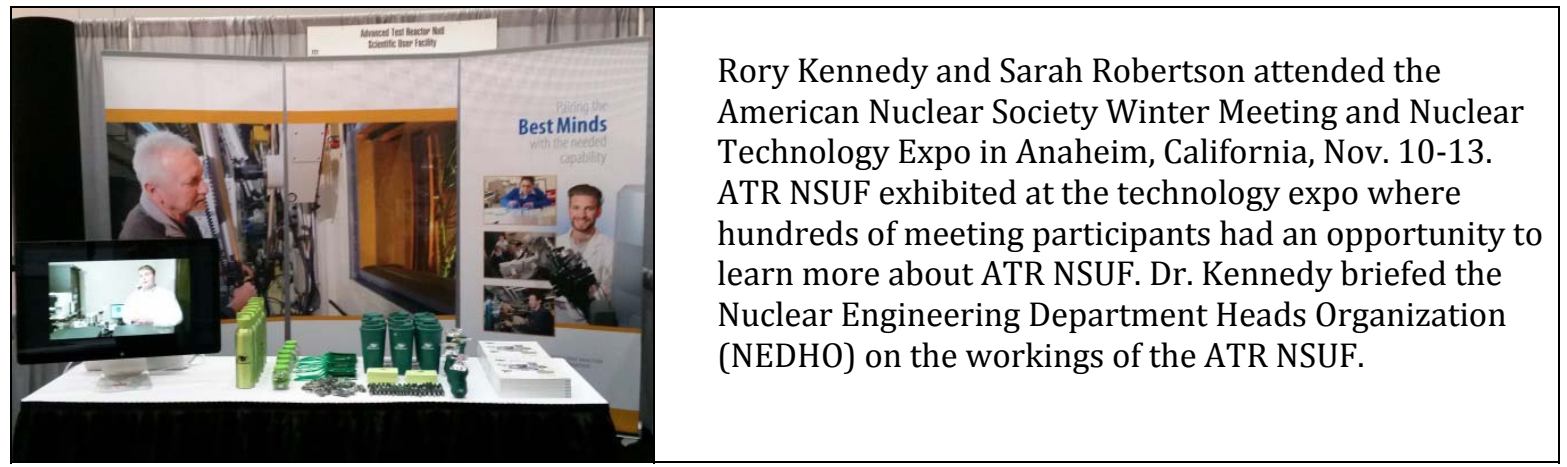

- Rory Kennedy, James Cole and Dan Ogden participated in a reactor instrumentation discussion with Jean-Francois Villard and Christopher Destouches of CEA and several members of the INL staff.

- ATR NSUF received approval from the NE-20 office to start planning the annual Users Meeting. The meeting will be held at INL, June 22-25.

- Mike Worley, director of the Office of Innovative Nuclear Research (NE-42), visited INL Nov. 4-5.

\section{Millestones Completed}

- Recommendations for the Summer Rapid Turnaround Experiment awards were submitted to DOEHQ Nov. 12 (Level 2 milestone due Nov. 30).

\section{Major Accomplishments/Activities}

- The University of California, Santa Barbara 2 experiment was unloaded from the GE-2000 at HFEF. The experiment specimen packs will be removed and shipped to ORNL for PIE.

- The Terrani experiment, one of three FY 2014 new awards, was completed utilizing the Advanced Photon Source MRCAT beamline. The experiment investigated the chemical state of Ag and Pd in SiC shell of irradiated TRISO particles via X-ray Absorption Fine Structure (XAFS) spectroscopy.

\section{Upcoming Meetings/Events}

- The ATR NSUF program review meeting will be held Dec. 9-10 at L'Enfant Plaza. In addition to NSUF staff and users, NE-4, NE-5 and NE-7 representatives will attend the meeting.

\section{Awarded Research Projects}

\section{Boise State University Rapid Turnaround Experiments (14-485 and 14-486)}

Nanoindentation and TEM work on the T91, HT9, HCM12A and 9Cr ODS specimens has been completed at CAES by Boise State PI Janelle Wharry and Cory Dolph. PI Corey Dolph returned in early November to complete their research by performing nanoindentation on unirradiated specimens that will be used as a baseline for their research. 


\section{North Carolina State University Rapid Turnaround Experiment (14-482)}

A new RTE for NCSU has been awarded for examination of nickel-based specimens from the NCSU A-capsule. The scope of work for this experiment is similar to what was completed for Ahmad Alsabbagh, with plans to look at nano- and regular-grain specimens using TEM, XRD, microhardness and tensile testing. SEM will be used to examine the fracture surface of the tensile specimens. The student PI, David Woodley, has completed TEM and hardness analysis of both the nano- and regular-grain materials. Samples have been sent to the Analytical Lab for XRD analysis. The brittle nature of the nanograin material has complicated analysis efforts, particularly with tensile testing. David Woodley has sent unirradiated specimens to MFC for analysis to provide a baseline for the data. Tensile specimens will be worked in FASB. The furnace has been removed from the load frame and is being readied for testing. SEM will be performed in FASB after testing is complete. Samples will be transferred to FASB once more detailed counting has been performed by the Analytical Lab. Completion of this work is pending authorization of radiological work in EML and FASB.

\section{University of Illinois (12-355)}

Thirteen tensile specimens have been prepared and loaded for shipment to APS. Only the specimens with a radiation exposure of $1 \mathrm{dpa}$ or less have dose rates $<5 \mathrm{mRem} / \mathrm{hr} @ 30 \mathrm{~cm}$, will be shipped, limiting the number of specimens available for testing in APS. The planned beam time at APS for April 10 was postponed until MRCAT resolved concerns over handling of the radioactive specimens. Cold testing has been performed by MRCAT and APS personnel. The new beam time has once again been delayed. The new date is expected in calendar year 2015. INL is ready to send the specimens as soon as authorization to ship is provided.

\section{Idaho State University MANTRA (09-197)}

Sample preparation on MANTRA 1 and 3 capsule specimens continued. Two shipments have been made to ATLAS to date. More shipments will be needed to complete MANTRA 1 and 3. Capsule 2 disassembly has been completed in HFEF and samples sent to Analytical Lab. Sample dissolution will begin once MANTRA 1 and 3 work is complete. Completion of this work is pending restart of radiological work in the Analytical Lab.

\section{Drexel MAX (09-204)}

XRD analysis of the TiAl and TiSiC specimens for capsules D, E and F has been completed. Eighteen specimens irradiated in the MIT reactor have been prepared and sent to CAES as well. Drexel PI Darin Tallman returned to CAES in November to perform FIB and TEM analysis on these MIT specimens (located at CAES). Darin will return to CAES in March, working towards completing his degree. Completion of this work is pending restart of radiological work in EML and FASB and the shipment of additional specimens from HFEF. Radiation readings have been completed in HFEF and are being reviewed to determine which specimens may be sent to EML.

Utah State University (09-157) - The 18 USU specimens have been prepared and shipped to FASB for laser flash and DSC analysis (nine specimens for DSC and nine for laser flash). DSC analysis has been completed. Laser flash has yet to begin because of the radiological work stand-down. XRD analysis has also been completed and results supplied to the PI (Donna Guillen). Five additional specimens have been transferred from EML to FASB for SEM analysis. Sample preparation has been extensive and SEM analysis has been completed. Results are being analyzed by an SEM subject matter expert. Completion of this work is pending restart of radiological work in EML and FASB and the shipment of additional specimens from HFEF. Radiation readings have been completed in HFEF and are being reviewed to determine which specimens may be sent to EML.

University of Central Florida (UCF) (10-242) - TEM and foil specimens will be moved from HFEF to EML in the coming months. Completion of this work is pending restart of radiological work in EML and the shipment of additional specimens from HFEF. Radiation readings have been completed in HFEF and are being reviewed to determine which specimens may be sent to EML. Design is progressing on UCF-2 (an ATR Hydraulic Shuttle Irradiation System) capsule set and UCF-3 (an ATR static capsule).

University of California-Berkley (UCB) (10-244) - Capsule analysis is continuing as outlined by the contract. Work is expected to be completed by the mid 2015.

University of California-Santa Barbara-2 (09-153) - The experiment was unloaded into the HFEF main cell and moved to the decontamination cell for storage until it can be disassembled and loaded into shipping 
pigs for shipment to ORNL. Isotopic calculations are being performed to support the shipment. With work delays in HFEF, shipment is expected in late January or early February.

\section{Cooperative Research Projects}

- A report summarizing the strain measurement and temperature measurement in the EPRI Zirconium Growth "B" capsule was issued to the sponsor (EPRI). This critical data allows comparison between the low fluence (capsule "A") and medium fluence (capsule "B") effects on zirconium alloys under boiling water reactor conditions.

- Repair of the IASCC test cell flywheel uninterruptable power supply was completed. This component is critical to operation of the IASCC test rigs, allowing uninterrupted operation of the rigs through power fluctuations.

- Initial preparations were made for the first post-test maintenance to be performed on the newly installed IASCC test cells. This initial maintenance will establish protocol for future maintenance operations on these cells.

\section{Infrastructure Management Initiative}

- Gap Analysis: The database was expanded with INL instrumentation from the Sunflower property management database. Additional information will be added in December from remaining INL facilities. The Database Review Committee charter and plan has been drafted, reviewed by NSUF management and forwarded to DOE-NE for review. The capabilities database and the review committee form the basis for the infrastructure part of the gap analysis.

- Database Review Committee: The revised charter was returned to DOE-NE for final review before inviting members and starting work. The MS Access database is being converted back to MS Excel format for easier review by committee members. The database has been reviewed by Export Control and will be sent though STIMS as an Excel spreadsheet in December.

- Major NE R\&D Capabilities: Worked with INL Property Management staff to add 274 new instruments to the Nuclear Energy Infrastructure Database (NEID) bringing the total to 702. These instruments are INL BEA or DOE-ID property with Federal Supply Code 66 (laboratory equipment) with initial purchase values above $\$ 50,000$ (does not include installation or maintenance costs). The Sunflower database system is used throughout the DOE complex to record information about the purchasing and disposition of capital equipment. Future efforts will expand this effort to the other DOE sites. A second facility survey is under review by NSUF management. This survey will query federal, commercial and university laboratories for specific information about instruments and facilities associated with irradiated materials research. 